\title{
Effect of Mortar Coating's Bond Quality on the Structural Integrity of Prestressed Concrete Cylinder Pipe with Broken Wires
}

\author{
Shaoqing $\mathrm{Ge}^{1} \&$ Sunil Sinha ${ }^{1}$ \\ ${ }^{1}$ Department of Civil and Environmental Engineering, Virginia Tech, USA \\ Correspondence: Shaoqing Ge, Department of Civil and Environmental Engineering, Virginia Tech, USA. \\ E-mail: geshaoqing@gmail.com
}

Received: February 11, 2015 Accepted: March 7, 2015 Online Published: June 2, 2015

doi:10.5539/jmsr.v4n3p59 URL: http://dx.doi.org/10.5539/jmsr.v4n3p59

\begin{abstract}
In North America, 90 out of 100 large water utilities utilize Prestressed Concrete Cylinder Pipe (PCCP) in their water transmission mains or force mains since 1942. This is mainly due to its low cost and relatively stable performance compared with other large-diameter pipe materials working under high-pressure. Though PCCP has relatively low failure rate, its failures usually occur without warning and can cause catastrophic consequences, threatening public safety. Most PCCP failures are caused by the breakage of prestressing wires that hold the pipe in compression. To be proactive and avoid PCCP failures, it is important to know the pipe condition and then take actions before it fails. Hence, numerical models have been developed to evaluate the pipe condition. However, current numerical models do not consider the bond between the presressing wires and mortar coating. Instead all broken wires are removed in the model. This is over-conservative and many good pipes had been misjudged to be "bad" pipes, causing unnecessary and very costly pipe excavation and replacement. To effectively and efficiently manage PCCP pipeline, it is very important to have a realistic modeling of the broken prestressing wires by considering the bond quality of the mortar coating.

This paper analyzes the effect of mortar coating's bond quality on PCCP's structural integrity. A theoretical approach is proposed to determine the length of broken wires losing prestress by considering the bond quality of the mortar coating. Based on the proposed method, a numerical model is developed and the pipe's structural integrity is analyzed. Several cases with different bond qualities of mortar coatings are analyzed in this paper. The results are then compared and summarized. The simulations results indicate that PCCPs with good mortar bond are not compromised much, while the assumptions of current models are too conservative. The research presented in this paper provides a better understanding of the importance of considering bond quality in modeling PCCP. The findings of this research can help utilities better management their PCCP pipelines with different bond qualities.
\end{abstract}

Keywords: Prestressed Concrete Cylinder Pipe (PCCP), PCCP failure, condition evaluation, numerical model, bond quality

\section{Introduction}

Prestressed Concrete Cylinder Pipe (PCCP) is a composite pipe material mainly composed of concrete, steel cylinder, mortar coating and prestressing wires (see Figure 1). The high-strength prestressing wire is drawn to a certain level of prestress to keep concrete core in great compression which can offset the tensile stress under normal working loadings. The mortar coating protects the prestressing wires from corrosion and determines the long-term durability of the pipe (Price et al., 1998; Wardany, 2008). The steel cylinder seal water from leaking. There are two type of PCCP (see Figure 2 and Figure 3): Lined Cylinder Pipe (LCP), and Embedded Cylinder Pipe (ECP). In LCP, the prestressing wires are wrapped around the steel cylinder which is outside of concrete core. In $\mathrm{ECP}$, the steel cylinder is embedded within concrete core, and the prestressing wires are wrapped around the concrete core (AWWA C301-07, 2007; ANSI/AWWA C304-07, 2007). PCCP has been widely used in water industry and more than 22,000 miles of PCCP has been installed in North America (Semanuik \& Mergelas, 2006; Romer et al., 2008).

PCCP has lower break rate compared with other pipe materials, however, its failure usually occurs suddenly without warning, leaving almost no time for utilities to respond. Due to the large size and high pressure inside the pipe, the failure can be catastrophic: flushing highways, houses, and other important neighboring infrastructures, causing millions dollars of loss. Moreover, the pipeline inspection and repairs following pipe failure is very costly 
as well (Bell, 2001; Essamin et al., 2005; Galleher and Stift, 1998). Miami-Dade had one 72-inch PCCP force main burst in 2010 and millions gallons of untreated wastewater flew into Biscayne Canal. They had to spend over 1 million dollars to fix the pipe, and received a penalty of approximately 1 million dollars (UIM, 2011; USEPA, 2013). In December 2008, a 66-inch PCCP failed on River Road, Maryland and trapped cars in flooding water. Helicopters had to be sent to rescue the drivers. Over 1.7 million dollars were spent to repair the pipe and over millions gallons of water was lost (WSSC, 2012).

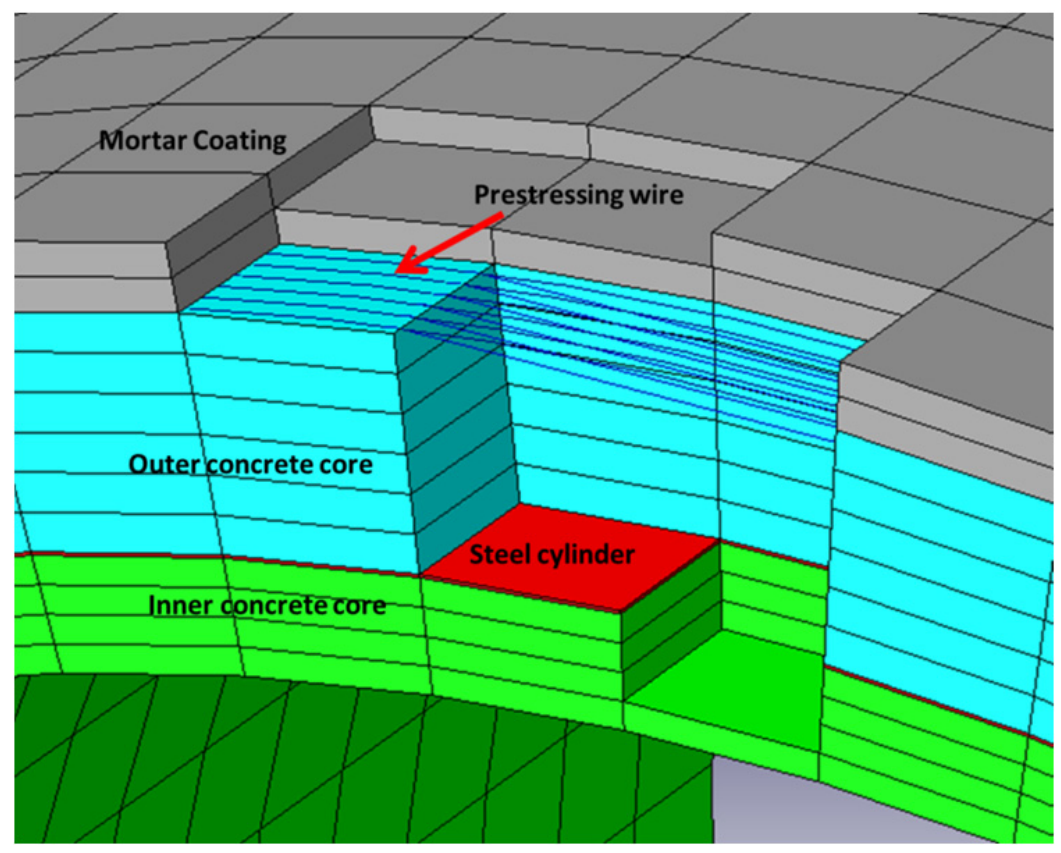

Figure 1. Pipe components in PCCP FE Model

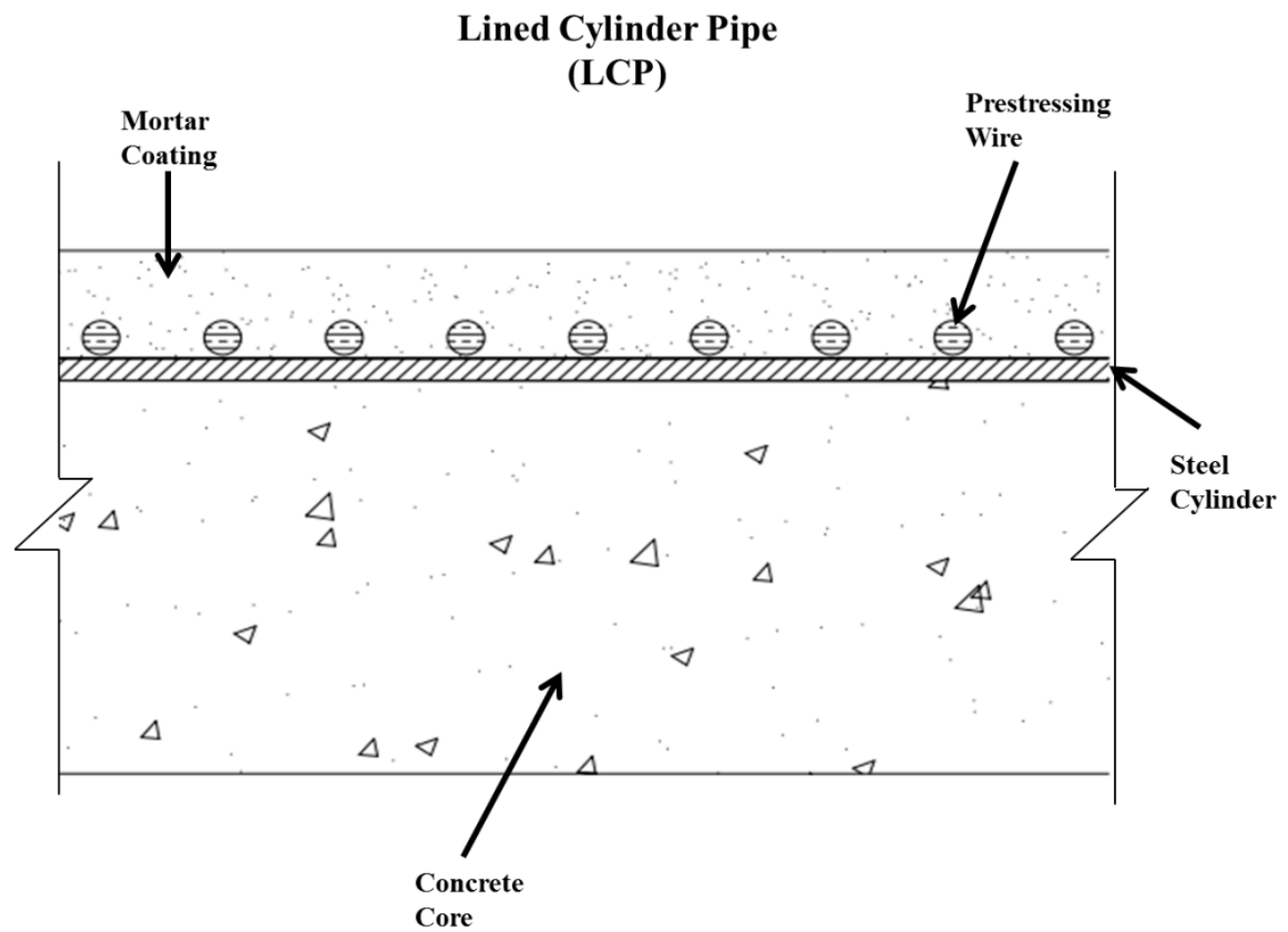

Figure 2. Lined Cylinder Pipe (LCP) 


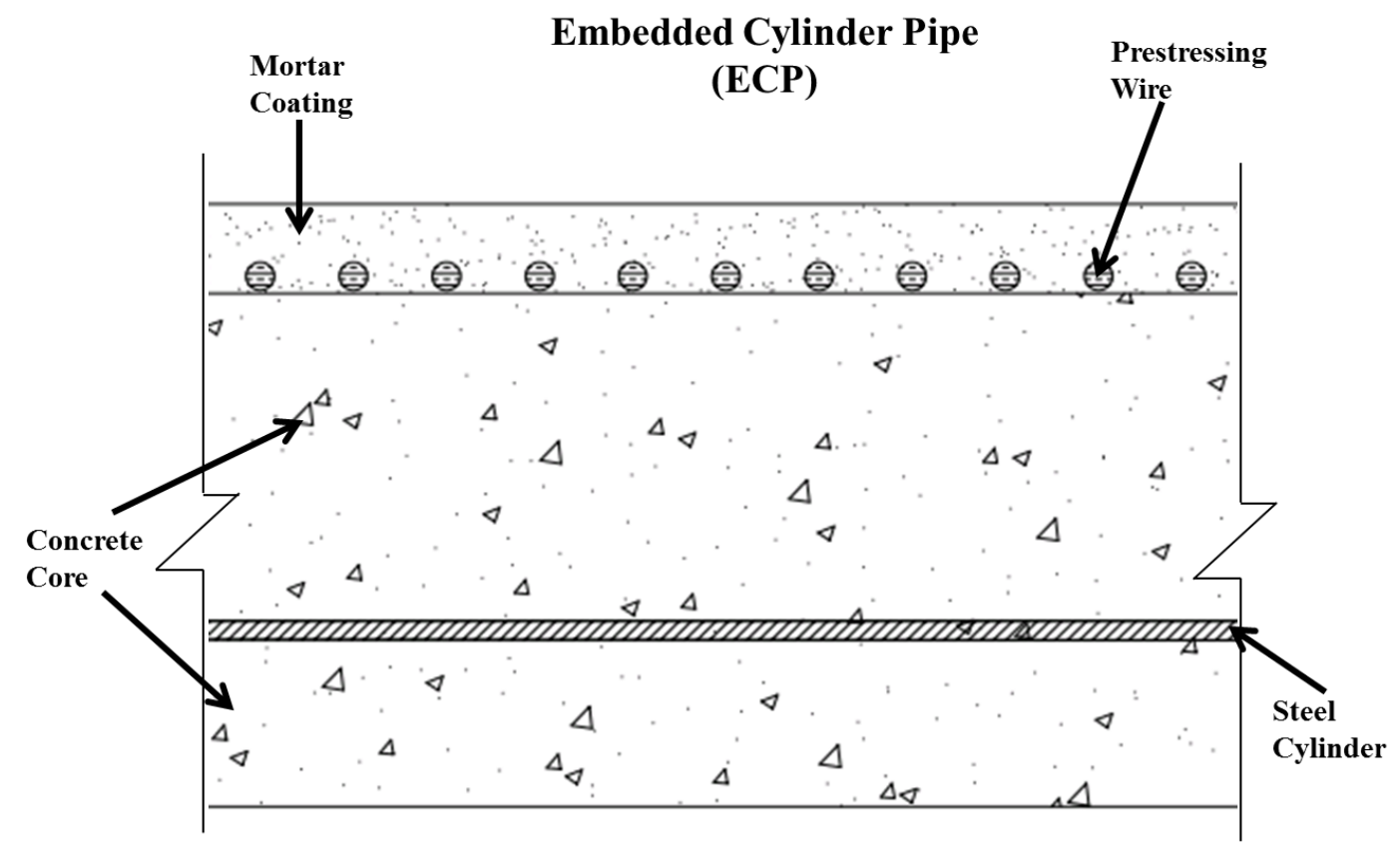

Figure 3. Embeded Cylinder Pipe (ECP)

PCCP failures are complicated and can be caused by factors that are grouped into three categories (AwwaRF, 2007; Walsh \& Hodge, 1998; Ojdrovic et al., 2001; Parks et al., 2001; Galleher \& Stift, 1998; Villalobos, 1998; Lewis, 2002): manufacture and design (poor bond, low prestress, poor material, etc.), construction and operation (poor bedding, construction damage, etc.), and environmental (corrosive soil, chloride, etc.). PCCP failure is usually initiated with "birth defects" such as cracks in coating caused in manufacture and construction, or overloading in operation. These cracks provide passage for chemicals in soil to reach the prestressing wires and steel cylinder and then corrosion starts. The hydrogen atom produced in corrosion process accumulates in prestressing wires and then it causes hydrogen embrittlement which makes the wire brittle and fail before it reach the ultimate tensile strength. The breakage of prestressing wires weakens the pipe structure and a critical number of breakages can cause concrete core to collapses and cylinder to burst (Price et al., 1998; Woodcock, 2008; Romer et al., 2008; Kola, 2010; Ge \& Sinha, 2012).

In practice, it was found that the prestress in the wire resumes beyond a certain length from the broken point of the wire (Gomez et al., 2004). Therefore, the broken wire still has prestress in certain portion between the broken point and the point where full prestress is resumed. Though most PCCP failures are caused by the breakage of prestressing wires, however, the bond quality between the prestressing wire and mortar coating is a critical factor, as it has been found in practice that PCCPs with good bond are not much compromised even though there are many broken wires. In contrast, for PCCPs with very poor bond, even fewer than normal number of broken wires could weaken pipe's structural integrity.

To mitigate catastrophic failures of PCCP, it is important to understand the remaining structure integrity of the pipe, so that proactive actions can be taken before it fails. To this end, considerable research has been conducted on developing numerical models to evaluate the structural integrity of the pipe. Zarghamee et al. (1993, 2001, 2002, 2003), Erbay et al. (2007), and Weare et al. (2007) established 3-dimetional models of PCCP using finite element method. These models take the nonlinear properties of the pipe materials into account. Loadings such as internal pressure, weight of soil cover, pipe and water are considered. However, all these models assume that broken wires have completely lost prestress and are removed from the simulation.

In some linear models developed by Diab and Bonierbale (2001), Gomez et al. (2004), and Alavinasab et al. (2010), the broken wires are either completely removed from the model or assumed to have a certain length removed based on rule of thumb. No robust analytical analysis or experimental verification has been conducted to account for the effect of bond quality of the mortar coating on PCCP's structural integrity.

Xiong et al. (2010) simulates the contact between the wire and concrete core for ECP using a new wire contact model to simulate the whole wire wrapping process. However, this model does not consider the bond between the 
prestressing wire and mortar coating. In other recent models (Lee, 2011; Rauniyar, 2013), the bond quality of mortar coating is not considered.

Current condition assessment technologies such as sonic/ultrasonic can provide qualitative information on prestress loss in prestressing wires. Further destructive tests are required to quantitatively measure the level of prestress in wires (Marshall \& Fisk, 2015).

In this paper, a theoretical approach is proposed to determine the length of prestressing wire losing prestressing once it breaks. Based on this approach, a numerical model is developed simulating different cases in which the mortar coating has different bond qualities.

\section{Methodology Proposed to Considerthe Bond Quality of MortarCoating}

To evaluate the pipe condition of PCCP with broken wires using numerical model, the key is to determine the range of broken wires losing prestress (or the length of broken wire needed to resume prestress in the wire) once the wire breaks, which depends on the bond quality of mortar coating. As is mentioned in introduction section, current numerical models for PCCP do not consider the bond quality of the mortar coating and all broken wires are assumed to have completely lost the prestress. In fact, because of the bond between the prestressing wire and mortar coating, after the wire breaks, it resumes prestress beyond a certain length (Gomez et al., 2004). So far, no lab tests have been conducted to determine the length needed to resume prestress in the broken wire due to the complexity, trickiness and high cost of the tests.

In this paper, an analytical methodology is proposed to calculate the length that a broken wire needs to resume prestress. It is assumed that the average bond strength of the mortar coating is $\sigma_{\text {bond }}$, the prestress in the prestressing wire is $\sigma_{\text {wire }}$, and the diameter of the prestressing wire is $D_{\text {wire }}$. Then, the length needed to resume the prestress is expressed below:

The analysis of this length is illustrated in Figure 4 and Figure 5. Based on the equilibrium of the broken wire, it can be expressed as:

$$
\left\{\begin{array}{l}
\sum F_{x}=0 \\
\sum F_{y}=0 \\
\sum M=0
\end{array}\right.
$$

From $\sum F_{x}=0$,

$$
-F_{1}+\int_{0}^{\theta} d F_{\text {bond }} \cdot \cos \frac{d \varphi}{2} \cdot+\int_{0}^{\theta} d N_{r} \cdot \sin \frac{d \varphi}{2}=0
$$

Where,

$d F_{\text {bond }}=\sigma_{\text {bond }} \cdot \pi \cdot D_{\text {wire }} \cdot d s$

$d N_{r}=q_{r} \cdot d s$ (radial stress increment)

$d s=R \cdot \varphi, R$ is the diameter of the turns of prestressing wires

$F_{1}=\sigma_{\text {wire }} \cdot \frac{\pi}{4} \cdot D_{\text {wire }}^{2}$

From $\sum F_{y}=0$, it is expressed as

$$
\int_{0}^{\theta} d F_{\text {bond }} \cdot \sin \frac{d \varphi}{2} \cdot-\int_{0}^{\theta} d N_{r} \cdot \cos \frac{d \varphi}{2}=0
$$

The sum of all the moments about point $O$ is zero, from $\sum M=0$,

$$
F_{1} \cdot R-\int_{0}^{\theta} d F_{\text {bond }} \cdot R=0
$$

Since the purpose is to calculate the range of the wire lost prestress, equation (4) can be used to get the results.

From equation (4), it can be derived as

$$
\begin{gathered}
\sigma_{\text {wire }} \cdot \frac{\pi}{4} \cdot D_{\text {wire }}^{2} \cdot R-\int_{0}^{\theta} \sigma_{\text {bond }} \cdot \pi \cdot D_{\text {wire }} \cdot R \cdot d \varphi \cdot R=0 \\
\sigma_{\text {bond }} \cdot R \cdot \theta=\sigma_{\text {wire }} \cdot \frac{1}{4} \cdot D_{\text {wire }}
\end{gathered}
$$


Thus,

$$
\begin{gathered}
\theta=\frac{\sigma_{\text {wire }}}{\sigma_{\text {bond }}} \cdot \frac{D_{\text {wire }}}{4 \cdot R} \\
L=\theta \cdot R
\end{gathered}
$$

The $\sigma_{\text {wire }}$ is generally around $1.09 \mathrm{e} 10 \mathrm{~Pa}(158,250 \mathrm{psi})$ and the average bond strength can be determined by direct tension pull-out lab test (Tastani \& Pantazopoulou, 2010).

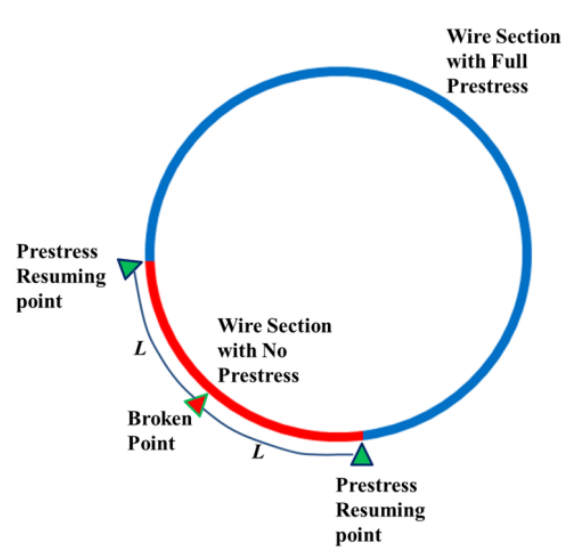

Figure 4. Prestress resuming in the broken wire of PCCP

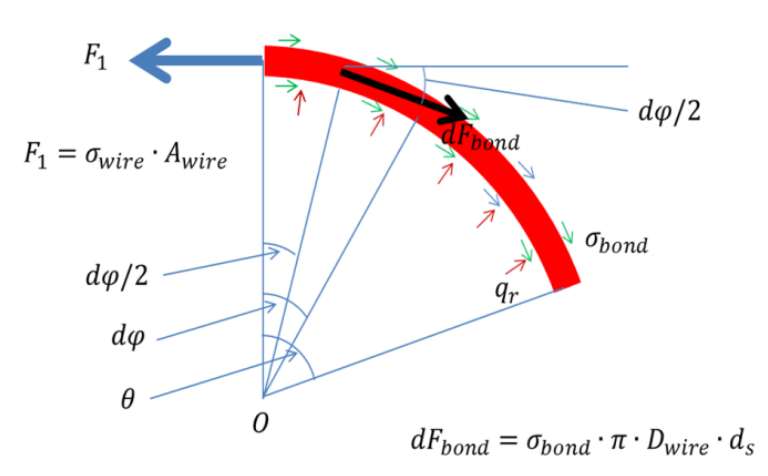

Figure 5. External forces acting on the broken wire

\section{Numerical Model for PCCP Considering Different Bond Quality}

Based on methodology proposed in section 2, a numerical model is developed using finite element method (FEM) to evaluate the effect of various bond quality of the mortar coating on the structural integrity of PCCP. In this numerical model, pipe components such as mortar coating, concrete core, prestressing wires, and steel cylinder are considered. These components are considered to stay connected without relative displacement along the interface of materials under loading conditions used in this paper. Loadings including weight of soil, pipe, and internal/surge pressure are considered. The FE model is shown in Figure 6. For boundary conditions, the bottom surface of the model is fully fixed; the top surface of the model is free; the surfaces of other four sides of the model are fixed in their normal directions.

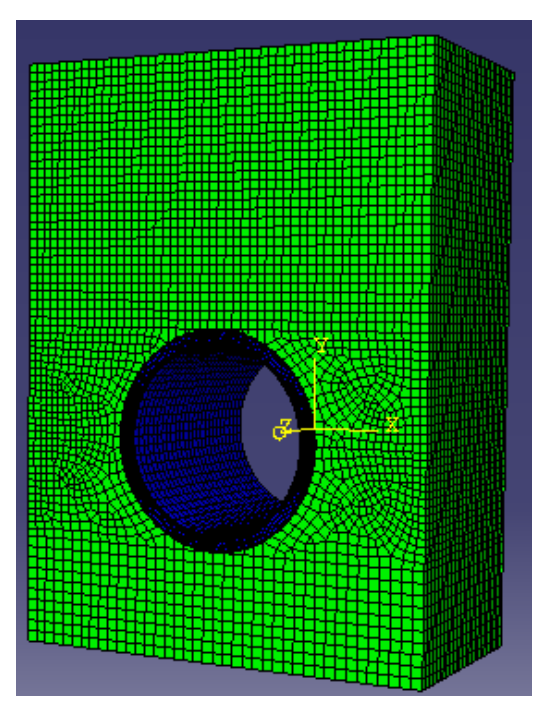

Figure 6. FE model of PCCP 
In this research, different wire bond strengths $\left(\sigma_{\text {bond }}\right)$ are compared to evaluate the effect of different bond qualities on PCCP's structural integrity. In the numerical model, the broken wires without full prestress are cut from the model, as is shown in Figure 7. Six cases studies are analyzed as below:

1) Case 1: Zero broken wires

2) Case 2: 40 broken wires, only prestress loss at broken point

3) Case 3: 40 broken wires, with $1 / 12$ of the broken wire lost prestress $\left(\theta=30^{\circ}\right)$

4) Case 4: 40 broken wires, with $1 / 6$ of the broken wire lost prestress $\left(\theta=60^{\circ}\right)$

5) Case 5: 40 broken wires, with $1 / 3$ of the broken wire lost prestress $\left(\theta=120^{\circ}\right)$

6) Case 6: 40 broken wires, the whole broken wire lost prestress, as is the assumption used in current numerical models.

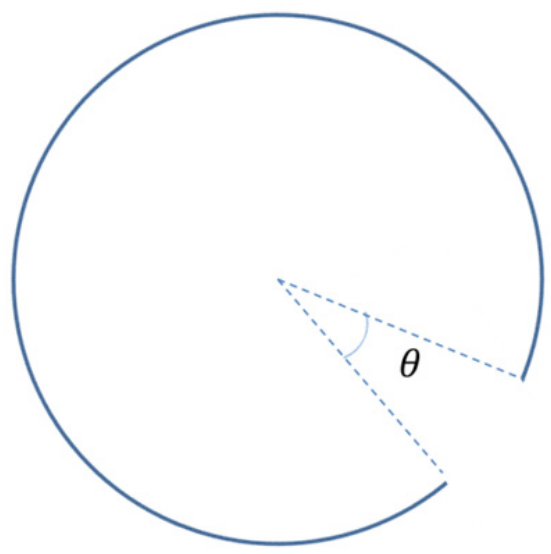

Figure 7. Broken wire model

In these six cases, the pipe (ECP) is subject to the loadings such as: soil, pipe and inside water weight, internal pressure $1.38 \mathrm{e} 6 \mathrm{~Pa}(200 \mathrm{psi})$, and surge pressure 5.52e $5 \mathrm{~Pa}(80 \mathrm{psi})$. The pipe dimensions are listed below:

- Pipe diameter: $1.68 \mathrm{~m}$ (66 inch)

- Cylinder thickness: $1.40 \mathrm{~mm}(0.05$ inch)

- Concrete core thickness: $0.13 \mathrm{~m}(5.00$ inch)

- Coating thickness: $0.02 \mathrm{~m}(0.81$ inch $)$

- Wire spacing: $0.01 \mathrm{~m}(0.43$ inch $)$

- $\quad$ Buried depth: $2.44 \mathrm{~m}(8 \mathrm{ft})$

The material properties used are listed in table below (Table 1):

Table 1. Mechanical property of materials

\begin{tabular}{llll}
\hline Material & Young's Modulus $(\mathrm{Pa})$ & Poisson's Ratio & Density $\left(\mathrm{kg} / \mathrm{m}^{3}\right)$ \\
\hline Concrete & $2.45 \mathrm{e}+10$ & 0.17 & 2322.61 \\
Soil & $6.90 \mathrm{e}+06$ & 0.25 & 1840.00 \\
Prestressing wire & $1.93 \mathrm{e}+11$ & 0.30 & 7832.80 \\
Cylinder & $2.07 \mathrm{e}+11$ & 0.30 & 7832.80 \\
\hline
\end{tabular}

Other properties of the materials include: Yield strength of the cylinder is $2.28 \mathrm{e}+8 \mathrm{~Pa}(33,000 \mathrm{psi})$ and its ultimate strength is $3.87 \mathrm{e}+8 \mathrm{~Pa}(56,100 \mathrm{psi})$. The wire ultimate strength is $1.45 \mathrm{e}+9 \mathrm{~Pa}(211,000 \mathrm{psi})$; and its wrapping stress is $1.09 \mathrm{e}+9 \mathrm{~Pa}(158,250 \mathrm{psi})$. Compressive strength of concrete is $48 \mathrm{MPa}(6,962 \mathrm{psi})$ and its tensile strength is 4.02 $\mathrm{MPa}(583 \mathrm{psi})$. The compressive strength of mortar coating is $37.90 \mathrm{MPa}(5,500 \mathrm{psi})$, and its tensile strength is 3.57 $\mathrm{MPa}(518 \mathrm{psi})$. In this research only elastic analysis is conducted due to unavailability of plastic properties of coating and concrete core. 
In the analysis of the six cases, the maximum principal stress at nodes in four strings (see Figure 8) are analyzed and compared to see the impacts caused by broken wires embedded in mortar coating with different bond qualities. The relative deformations in horizontal direction is analyzed and summarized to see how the deformation of the pipe is affected in each case (see Figure 9). The vertical deformation change is not provided because the change in horizontal direction can represent the deformation of the pipe.

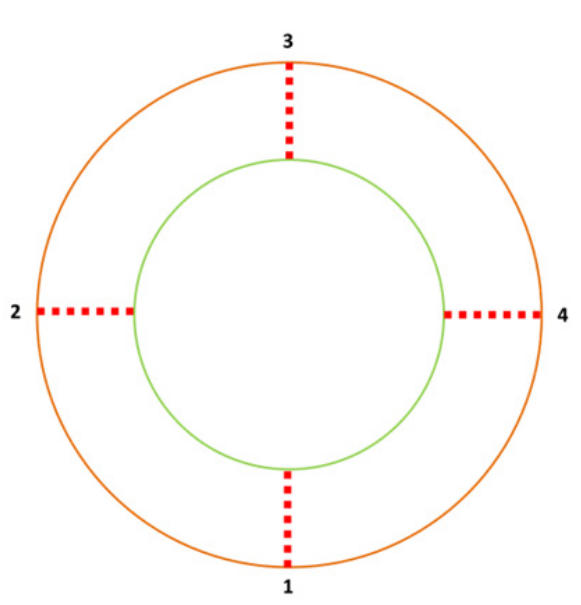

Figure 8. Locations of pipe for stress evaluation

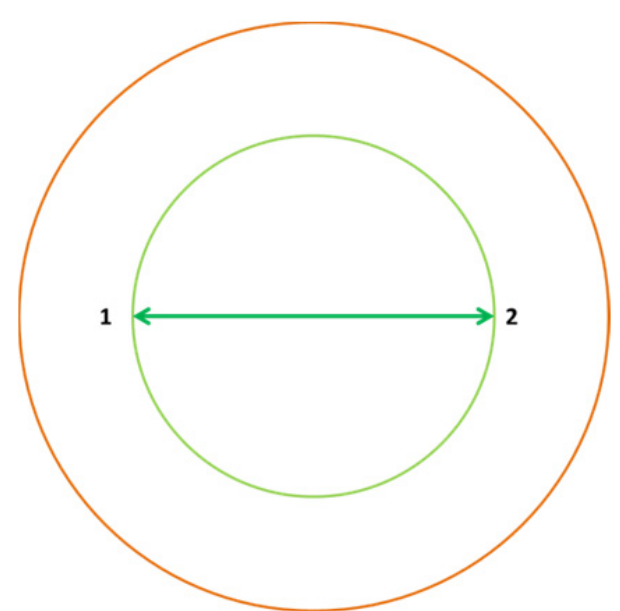

Figure 9. Relative deformations

\subsection{Case 1: Zero Broken Wires}

In this case, there are no broken wires in the model. This case is analyzed to compare with the results of other cases in which the PCCP has broken wires and its mortar coating has different bond strengths. The maximum principal stress in mortar coating and concrete core is shown in Figure 10. The stress distribution in the middle section of the pipe is shown in Figure 11.

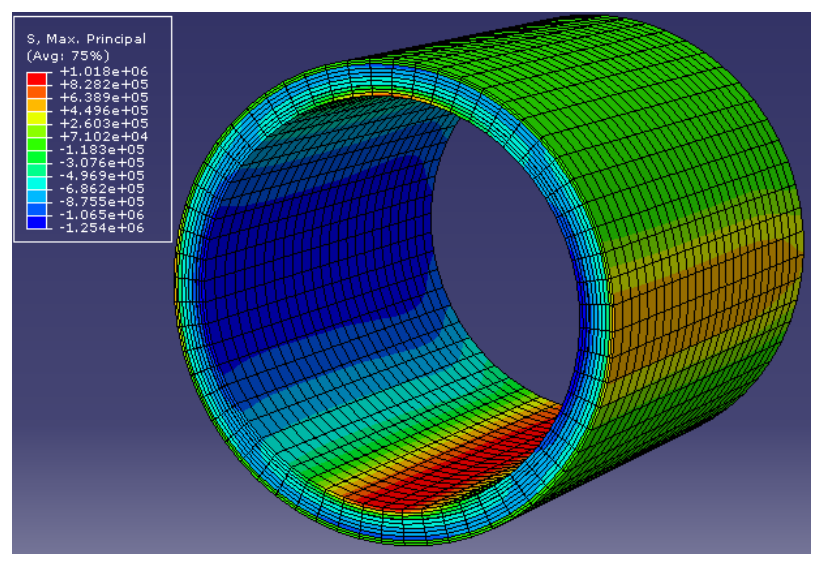

Figure 10. Maximum principal stress in PCCP (Case 1)

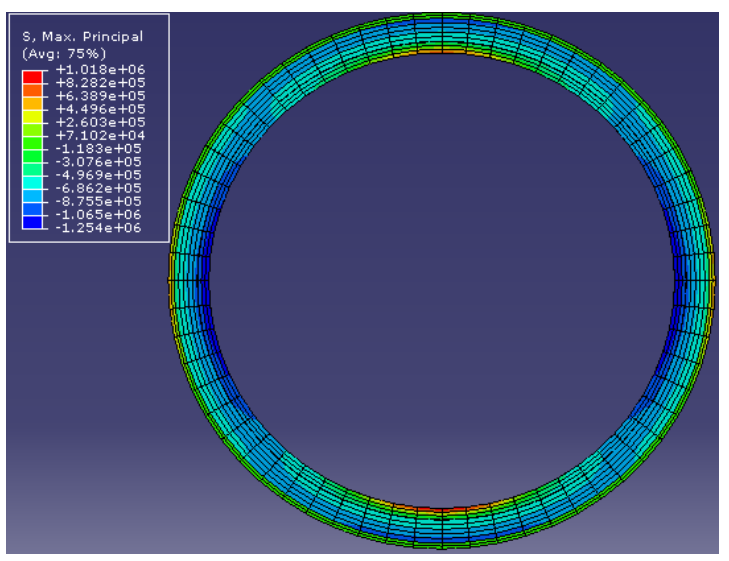

Figure 11. Maximum Principal stress in the middle section of PCCP (Case 1)

The maximum principal stress at nodes in four strings (Figure 8) of middle section of the pipe is shown Figure 12. According to Figure $10-12$, for PCCP without any broken wire, under the specified loading conditions, the maximum principal stress is $1.00 \mathrm{MPa}$ and it is located at invert of the pipe. Since the maximum principal stress is lower than the tensile strength of concrete $(4.02 \mathrm{MPa})$, there is no cracks in the pipe. The deformation of the whole model in horizontal direction is shown in Figure 13 and the horizontal deformation in middle section is shown in Figure 14. According to Figure 13 and Figure 14, the maximum horizontal deformation is $0.77 \mathrm{~mm}$. In Figure 14, because of symmetry, the stress at nodes in String 2 and String 4 are exactly the same. String 1 and String 3 have slight difference in the nodes close to the interior side of the pipe, and String 1 (invert) has bigger tensile stress compared to String 3 (crown). 


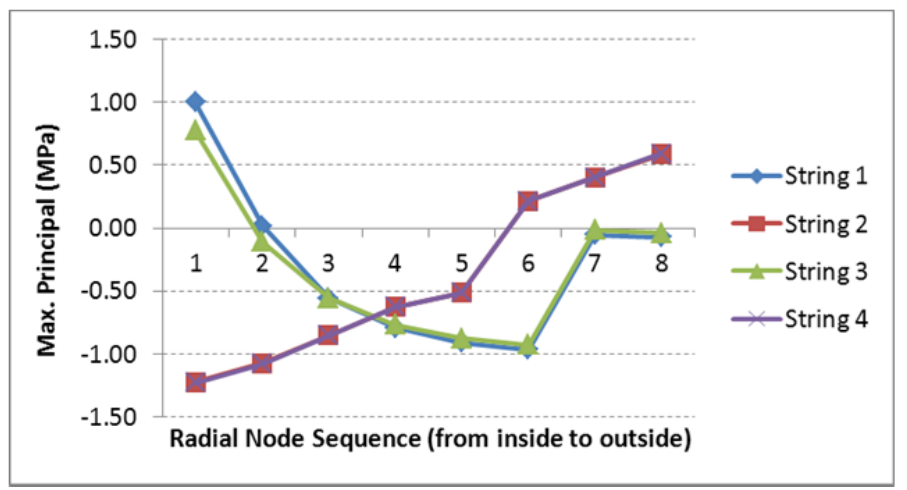

Figure 12. Maximum Principal stress at nodes in four strings in the middle section of PCCP (Case 1)

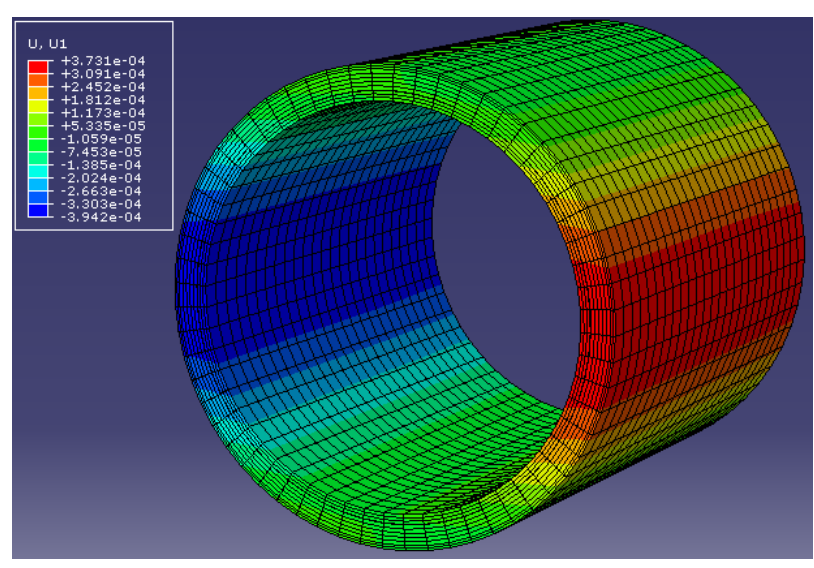

Figure 13. Horizontal deformation of PCCP (Case 1)

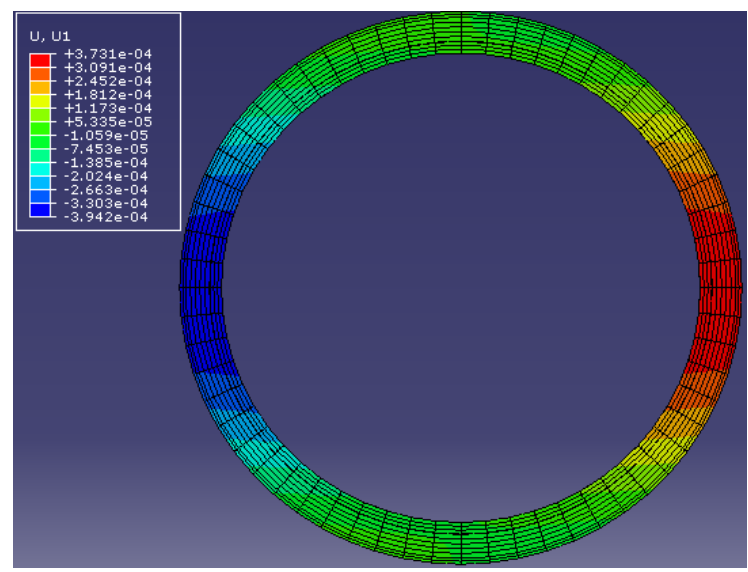

Figure 14. Horizontal deformation in the middle section of PCCP (Case 1)

\subsection{Case 2: 40 Broken Wires, Only Prestress Loss at Broken Point}

In this case, there are 40 broken wires in the middle of the model. However, because of the strong bond between the prestressing wire and mortar coating, there is prestress loss only at the point where the wire breaks. The maximum principal stress in mortar coating and concrete core is shown in Figure 15. The stress distribution in the middle section of the pipe is shown in Figure 16.

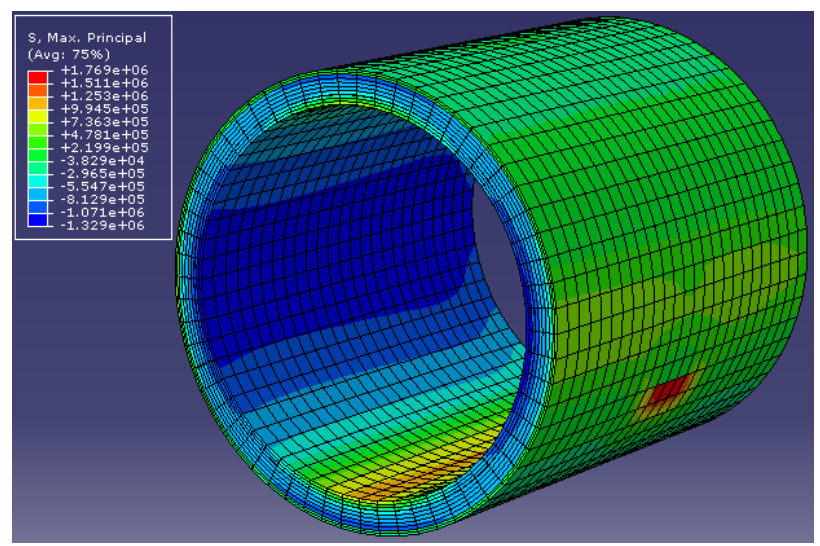

Figure 15. Maximum principal stress in PCCP (Case 2)

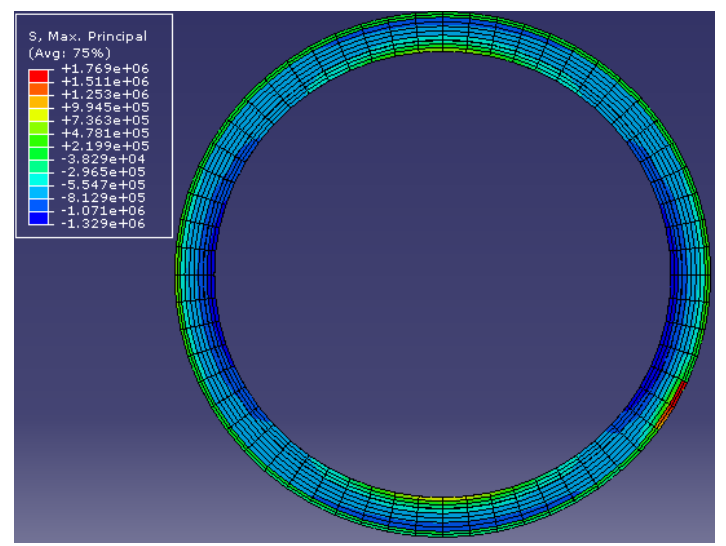

Figure 16. Maximum Principal stress in the middle section of PCCP (Case 2)

The maximum principal stress of the four strings in the middle section of the pipe is shown in Figure 17. According to Figure 15-17, the maximum principal stress is $1.00 \mathrm{MPa}$ and it is located in mortar coating near the broken point 
of the prestressing wire. As the maximum principal stress is lower than the tensile strength of mortar coating (3.57 $\mathrm{MPa})$, there is no crack in the coating. The deformation of the whole model and in middle section is shown in Figure 18 and Figure 19. The maximum horizontal deformation is $0.77 \mathrm{~mm}$, almost the same compare with Case 1. In Figure 19, the stress at nodes in String 2 and String 4 are almost the same. In general, the stress and deformation distribution is very close to that in Case 1 . This is because the pipe is not much compromised since there is only prestress loss at the broken point of the prestressing wires.

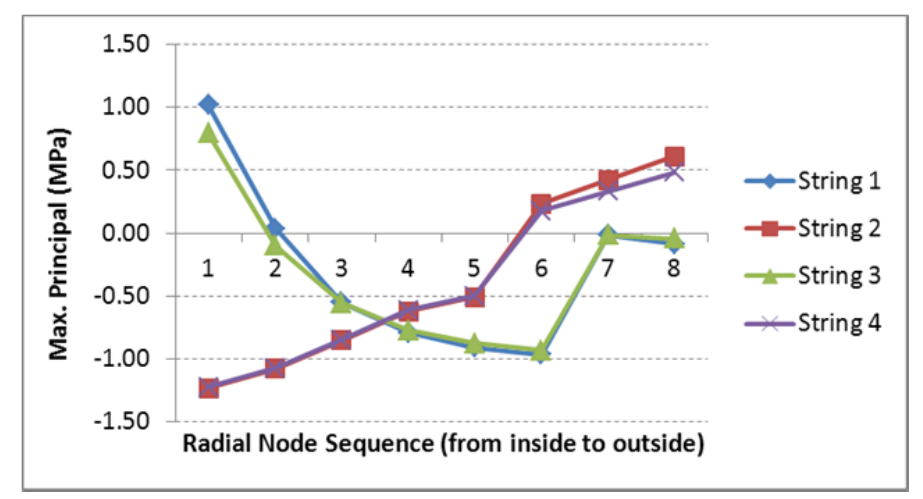

Figure 17. Maximum Principal stress at nodes in four strings in the middle section of PCCP (Case 1)

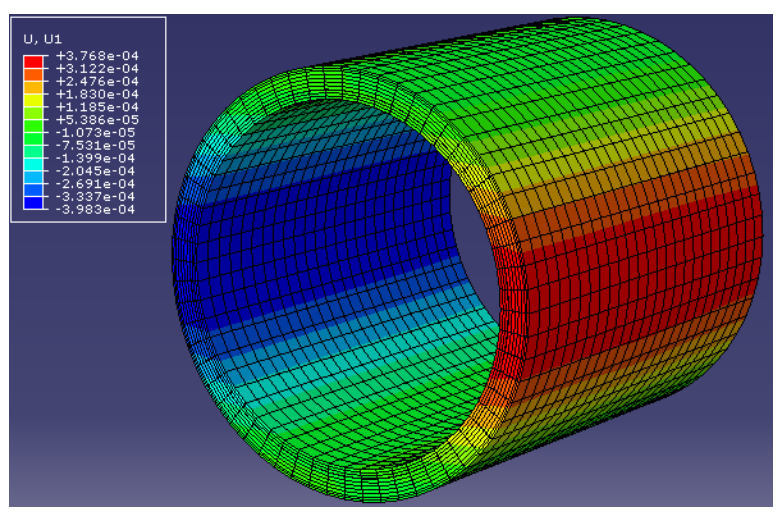

Figure 18. Horizontal deformation of PCCP (Case 2)

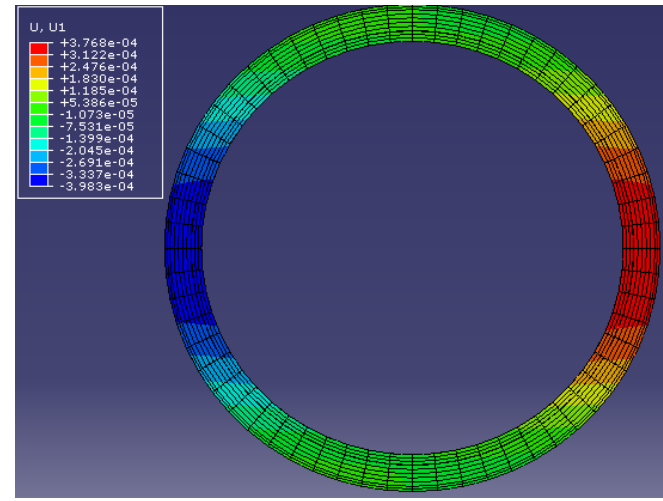

Figure 19. Horizontal deformation in the middle section of PCCP (Case 2)

\subsection{Case 3: 40 Broken Wires, with 1/12 of the Broken Wire Lost Prestress}

In this case, the pipe has 40 broken wires and because of lower mortar bond strength, the range of prestress wire losing prestress increased to $1 / 12$ of the whole wire turn. The distribution of maximum principal stress is shown in Figure 20 and Figure 21. The maximum principal stress of the four strings in the middle section of the pipe is shown in Figure 22. According to Figure 20-22, the maximum principal stress is $19.72 \mathrm{MPa}$ and it is located in mortar coating near the broken point of the prestressing wire. This stress is much higher than the tensile strength of mortar coating (3.57 MPa), so the coating will crack. As is shown in Figure 21, the concrete core in the broken wire zone near the prestressing wire has very high tensile stress (higher than the tensile strength of concrete), therefore, there could also cracks in the concrete core. Figure 22 shows that nodes in string 4 generally have higher stress than nodes in string 2, this is because it is closer to broken wire zone and received more transferred load.

The deformation of the whole model and in middle section is shown in Figure 23 and Figure 24. The maximum horizontal deformation is $0.88 \mathrm{~mm}$, a little higher than that in Case 1 and Case 2. From Figure 23 and Figure 24, it can be seen that there is much higher deformation in the broken wire zone compared with other locations of the pipe. 


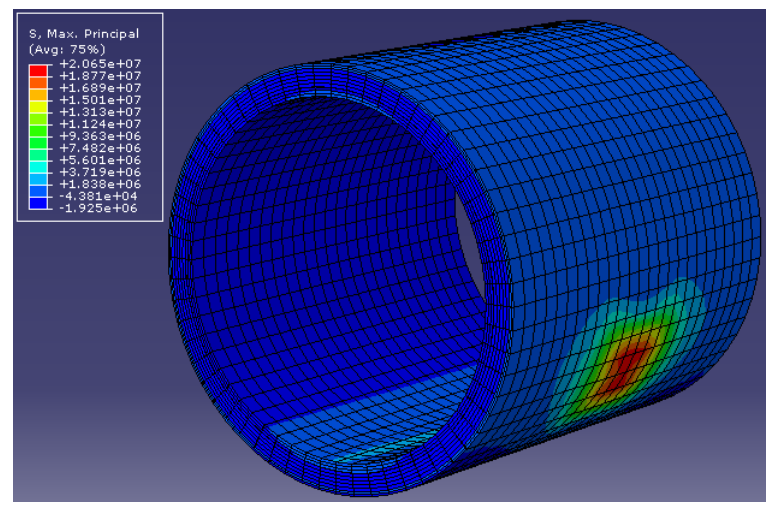

Figure 20. Maximum principal stress in PCCP (Case 3)

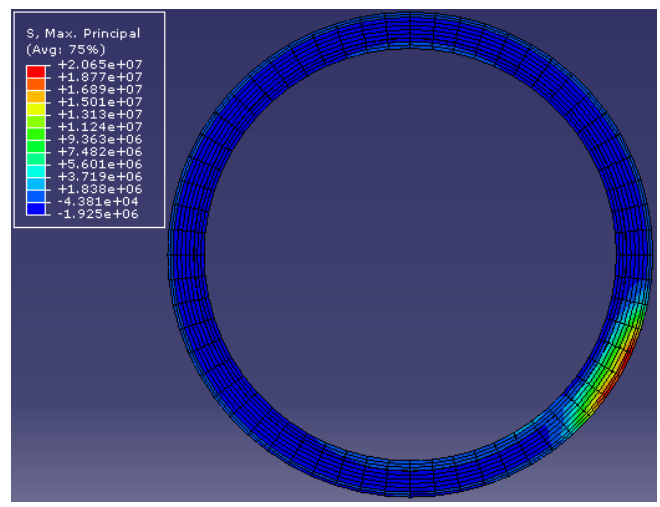

Figure 21. Maximum Principal stress in the middle section of PCCP (Case 3)

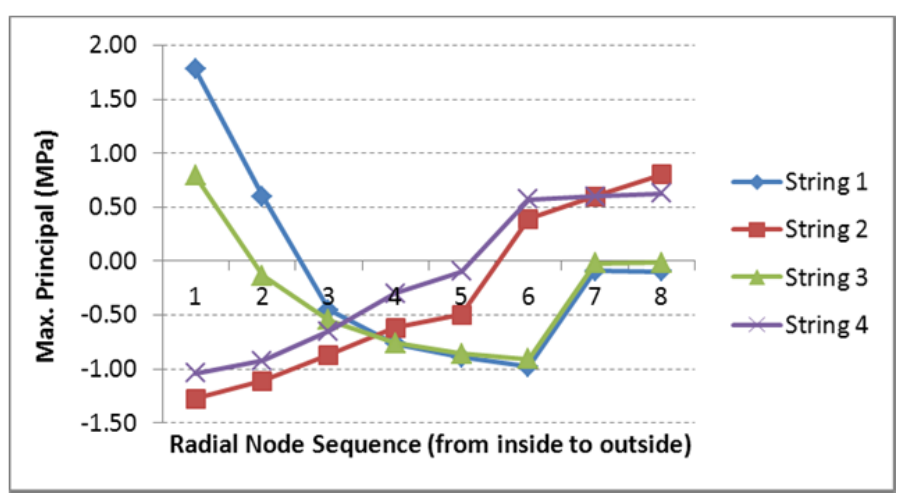

Figure 22. Maximum Principal stress at nodes in four strings in the middle section of PCCP (Case 3)

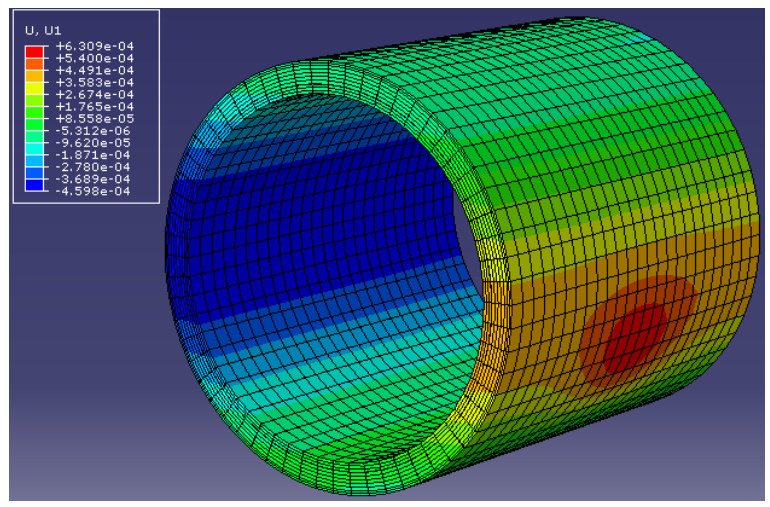

Figure 23. Horizontal deformation of PCCP (Case 3)

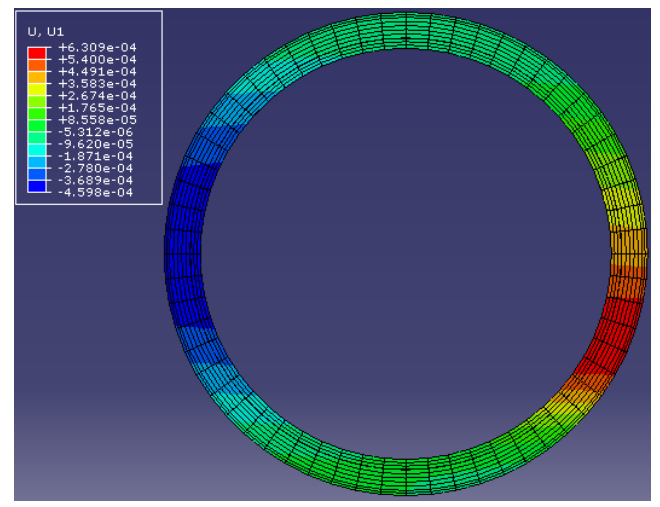

Figure 24. Horizontal deformation in the middle section of PCCP (Case 3)

\subsection{Case 4: 40 Broken Wires, with 1/6 of the Broken Wire Lost Prestress}

In this case, the pipe has 40 broken wires and the range of prestress wire losing prestress increased to $1 / 6$ of the whole wire turn. The distribution of maximum principal stress is shown in Figure 25 and Figure 26. The maximum principal stress of the four strings in the middle section of the pipe is shown in Figure 27. According to Figure 25-27, the maximum principal stress is $27.33 \mathrm{MPa}$ and it is located in mortar coating near the broken point of the prestressing wire. This stress is much higher than the tensile strength of mortar coating (3.57 MPa), so the coating will crack. As is shown in Figure 26, the concrete core in the broken wire zone near the prestressing wire also has very high tensile 
stress (higher than the tensile strength of concrete), and there could also be cracks in the concrete core. Figure 27 shows that nodes in string 4 has very high tensile stress due to the load transferred from the broken wires.

The deformation of the whole model and in middle section is shown in Figure 28 and Figure 29. The maximum horizontal deformation is $1.10 \mathrm{~mm}$, much higher than that in Case 1, Case 2 and Case 3. Figure 28 and Figure 29 show that there is much higher deformation in the broken wire zone compared with other locations of the pipe.

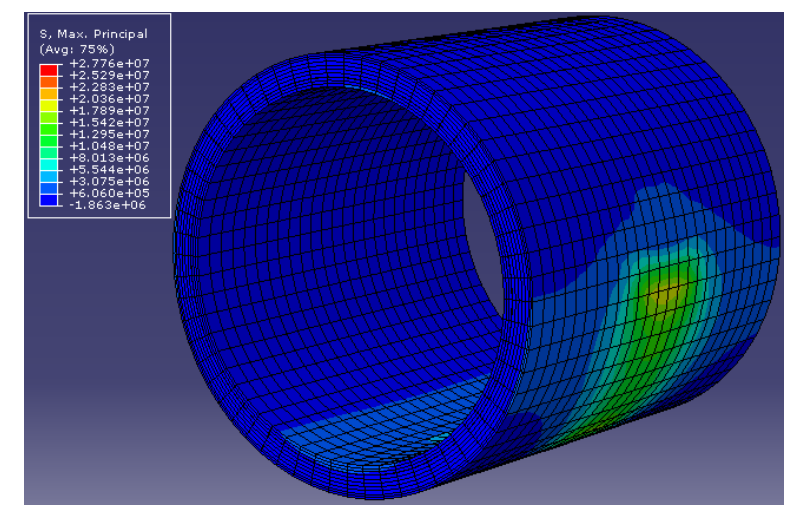

Figure 25. Maximum principal stress in PCCP (Case 4)

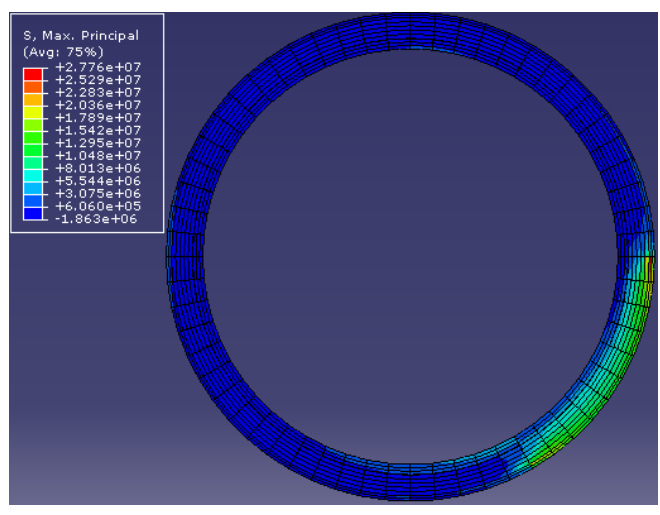

Figure 26. Maximum Principal stress in the middle section of PCCP (Case 4)

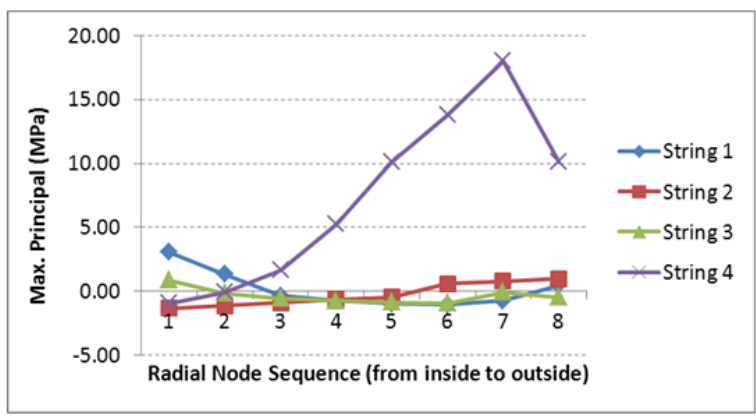

Figure 27. Maximum Principal stress at nodes in four strings in the middle section of PCCP (Case 4)

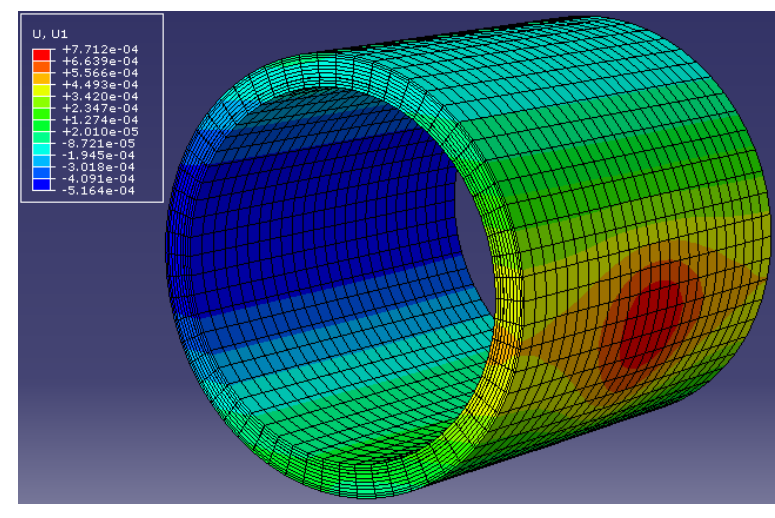

Figure 28. Horizontal deformation of PCCP (Case 4)

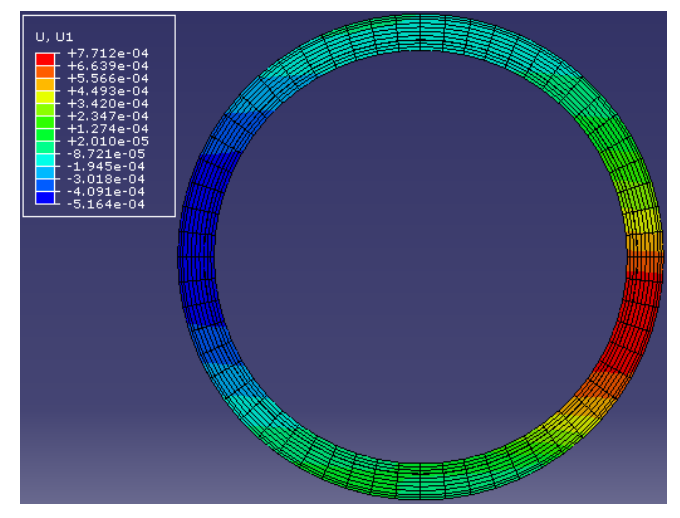

Figure 29. Horizontal deformation in the middle section of PCCP (Case 4)

\subsection{Case 5: 40 Broken Wires, with 1/3 of the Broken Wire Lost Prestress}

In this case, the pipe has 40 broken wires and the range of prestress wire losing prestress increased to $1 / 3$ of the whole wire turn. Figure 30 and Figure 31 shows the distribution of maximum principal stress. Figure 32 shows the 
maximum principal stress of the four strings in the middle section of the pipe. From Figure 30-32, it can be seen that the maximum principal stress is $25.31 \mathrm{MPa}$ and it is located in mortar coating near the broken point of the prestressing wire. This stress is much higher than the tensile strength of mortar coating (3.57 MPa), so the coating will crack. From Figure 31, it can be seen that the concrete core in the broken wire zone near the prestressing wire also has very high tensile stress (higher than the tensile strength of concrete), and there could also be cracks in the concrete core. Figure 32 shows that nodes in String 1 and 4 have very high tensile stress because they are very close to the broken point of the prestressing wire.

The deformation of the whole model and in middle section is shown in Figure 33 and Figure 34. The maximum horizontal deformation is $1.26 \mathrm{~mm}$ and there is much higher deformation in the broken wire zone compared with other locations of the pipe.

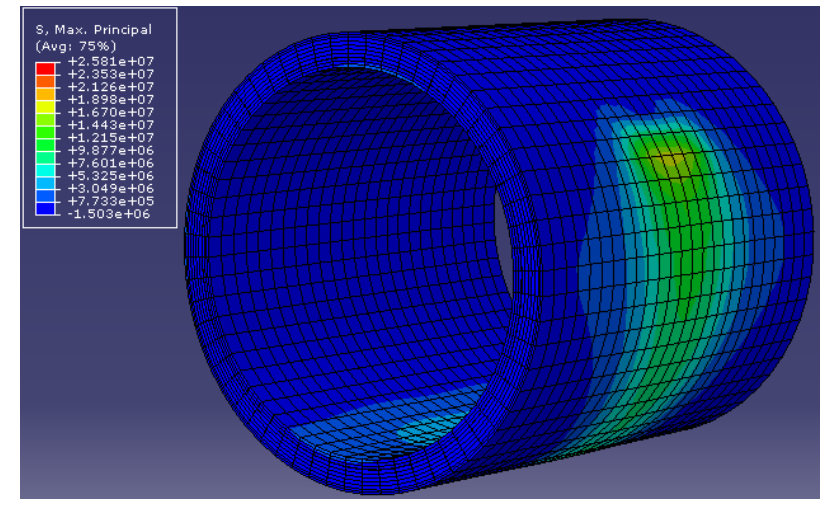

Figure 30. Maximum principal stress in PCCP (Case 5)

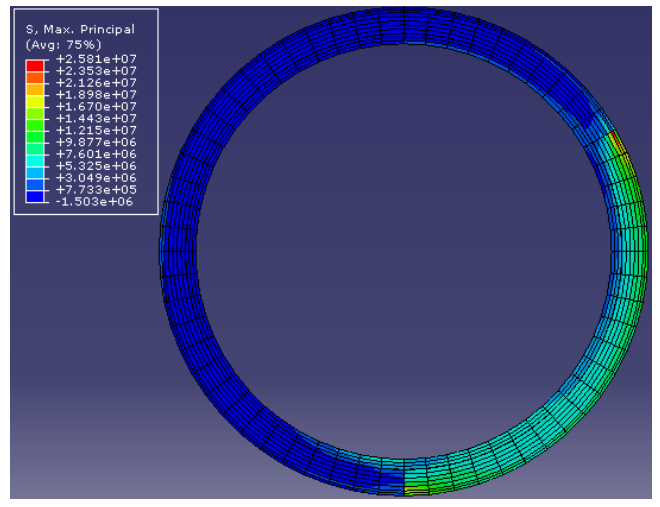

Figure 31. Maximum Principal stress in the middle section of PCCP (Case 5)

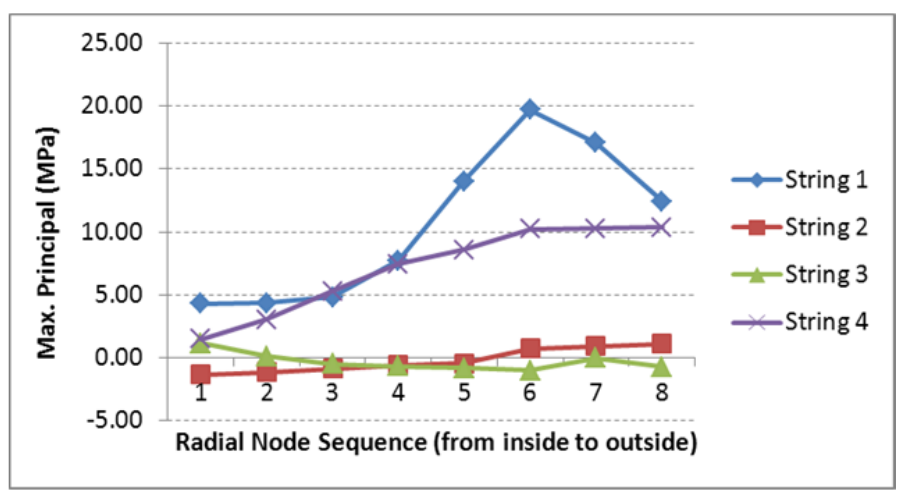

Figure 32. Maximum Principal stress at nodes in four strings in the middle section of PCCP (Case 5)

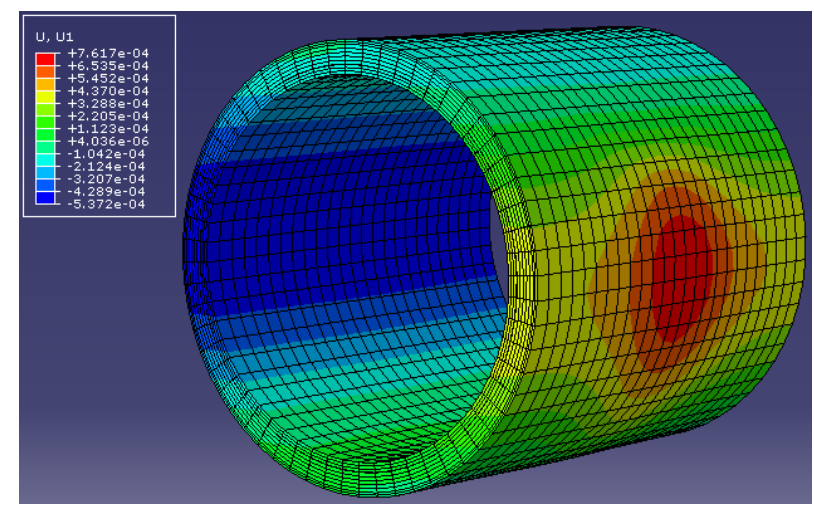

Figure 33. Horizontal deformation of PCCP (Case 5)

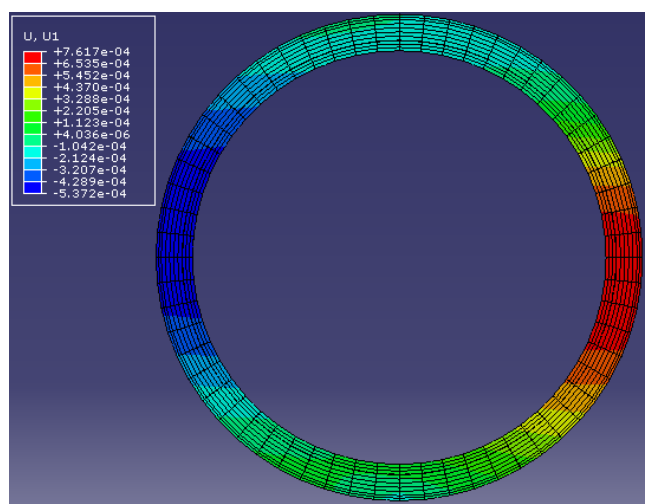

Figure 34. Horizontal deformation in the middle section of PCCP (Case 5) 


\subsection{Case 6: 40 Broken Wires, with the Whole Broken Wire Lost Prestress}

In this case, all the 40 broken wires lost prestress and they are removed out of the model. This is exactly what the current models assume and do. Figure 35 and Figure 36 shows the distribution of maximum principal stress. Figure 37 shows the maximum principal stress of the four strings in the middle section of the pipe. From Figure 35-37, it can be seen that the maximum principal stress is $9.39 \mathrm{MPa}$ and it is located at the invert of the pipe in the broken wire zone. This stress is much higher than the tensile strength of concrete $(4.02 \mathrm{MPa})$, so the coating will crack here. Figure 36 shows that much of the concrete core in the broken wire zone has very high tensile stress (higher than the tensile strength of concrete). Figure 37 shows that nodes in String 2 and 4 have the same stress because of symmetry. Compared with other cases, this case shows cracks at invert, crown inside the pipe and springlines outside the pipe. Though the maximum principal stress is lower compared with other cases, the case shows the most severe condition of the pipe.

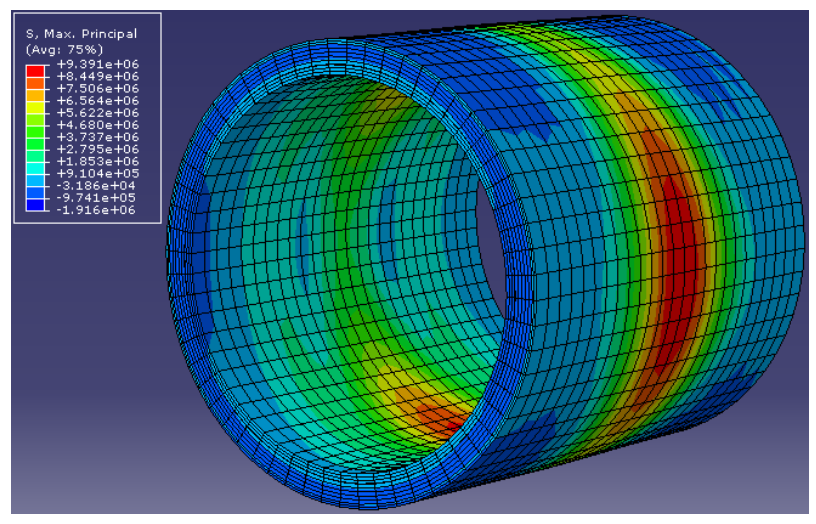

Figure 35. Maximum principal stress in PCCP (Case 6)

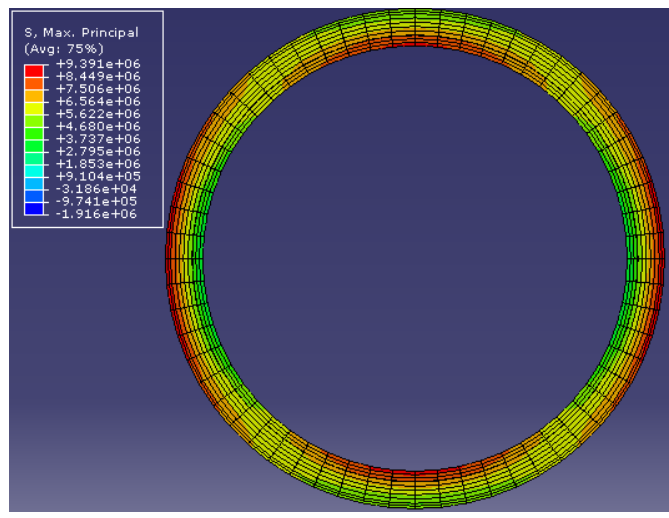

Figure 36. Maximum Principal stress in the middle section of PCCP (Case 6)

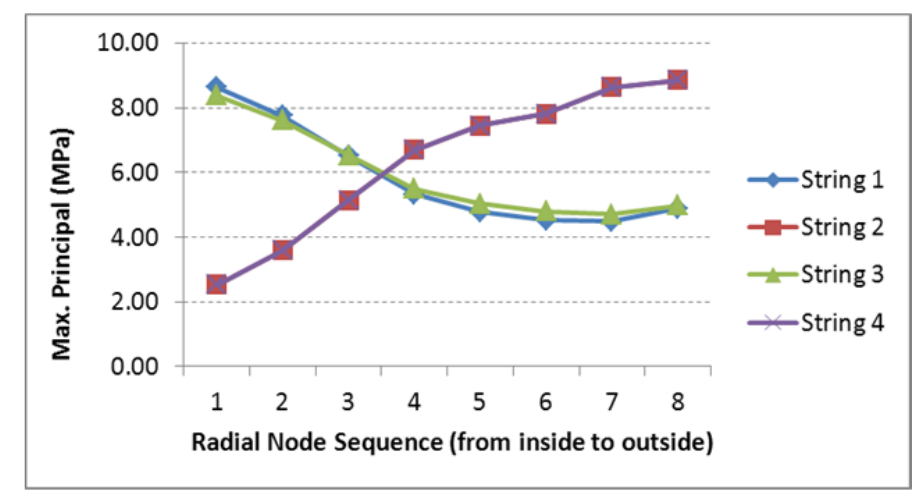

Figure 37. Maximum Principal stress at nodes in four strings in the middle section of PCCP (Case 6)

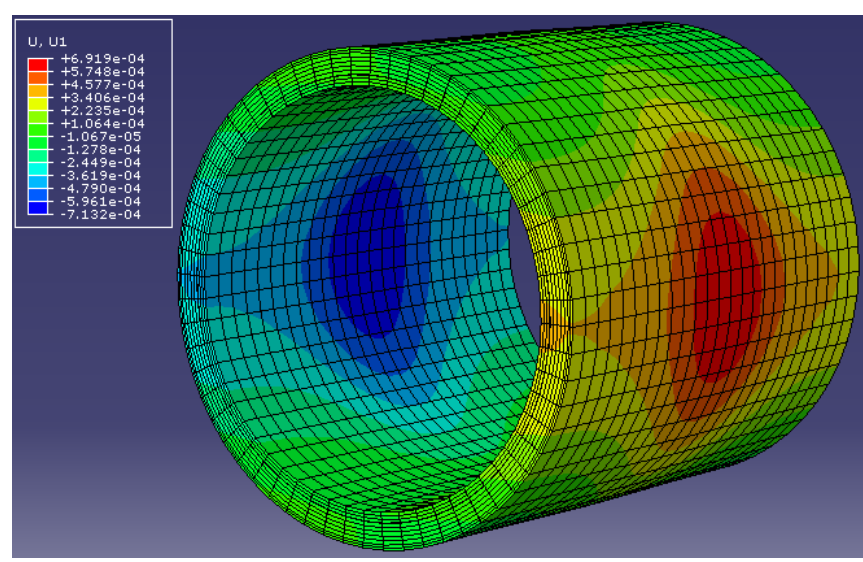

Figure 38. Horizontal deformation of PCCP (Case 6)

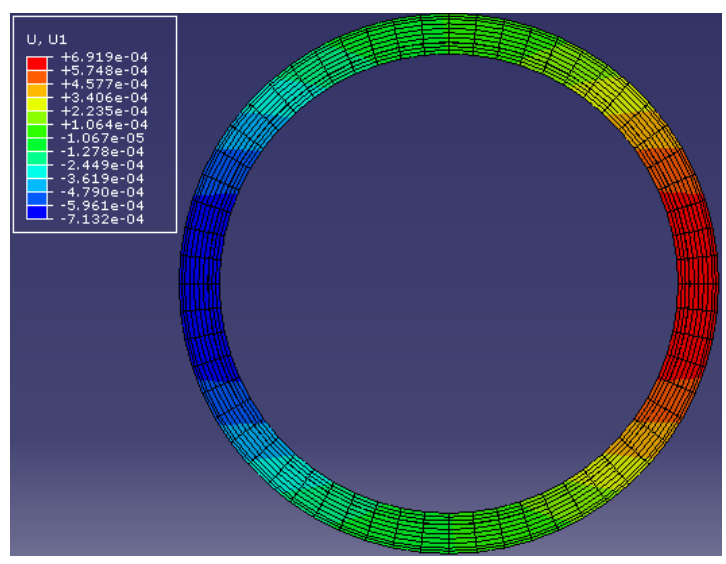

Figure 39. Horizontal deformation in the middle section of PCCP (Case 6) 
The deformation of the whole model and in middle section is shown in Figure 38 and Figure 39. The maximum horizontal deformation is $1.37 \mathrm{~mm}$, much higher compared with previous cases. From this case, it can be seen that assuming all prestress in broken wires is lost is too conservative. This is not consistent with the actual failure mode of PCCP. In practice, most failures fail at 4 or 8 o'clock in circumferential position. In the investigation of actual failures of PCCP, most pipes burst at these positions. However, according to this conservative assumption, after removing all broken wires from the model, the maximum tensile stress occurs in the invert of the pipe and springline.

\section{Summary of PCCPs with Various Bond Quality}

The maximum principal stress of nodes in four strings of each case is summarized to understand the impact of broken wires with different bond quality on the structural integrity of the pipe. The stress at nodes in each string is shown in Figure 40-43. In Figure 40, since the broken wires are cut at around string 1, there is stress concentration in this location. Same is for String 4 in Case 4 shown in Figure 40, the broke wire is cut at around String 4 and stress concentration generates in this location. In general, case 1 and case 2 have very close in almost all String positions. This is because, even though there are broken wires, if the wire bond is very good and no prestress loss in the prestress wires, the pipe is almost not compromised. As the range of broken wires losing prestress increase, the number of nodes with stress higher than tensile strength increases, this is because more load which has been born by the prestressing wires is transferred to the surrounding concrete core and coating. Though in Case 4 and 5 there are locations with very high tensile stress, the total zone with high tensile stress is smaller compared with Case 6 which shows the whole broken wire zone is in danger of cracking. However, if the prestress wires have only a small range without prestress as is shown in Case 2 and Case 3, the pipe is still in good condition with any crack.

The horizontal deformations of the pipe in broken wire zone and non-broken wire zone are compared in Figure 44, which shows that the horizontal deformation in the broken wire zone increases as the range of broken wire without prestress increases. Similarly, the difference of the horizontal deformation between broken wire zone and non-broken wire zone increases, which is consistent with the increase of maximum principal stress in the pipe.

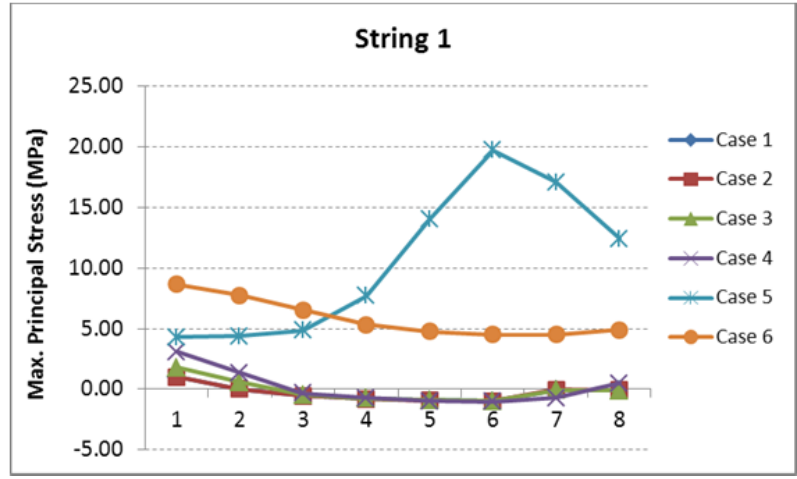

Figure 40. Maximum Principal stress at nodes in Strings 1

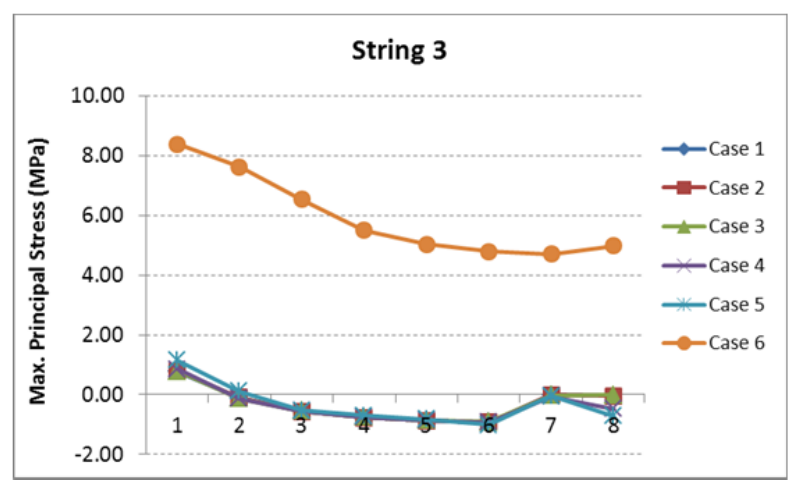

Figure 42. Maximum Principal stress at nodes in Strings 3

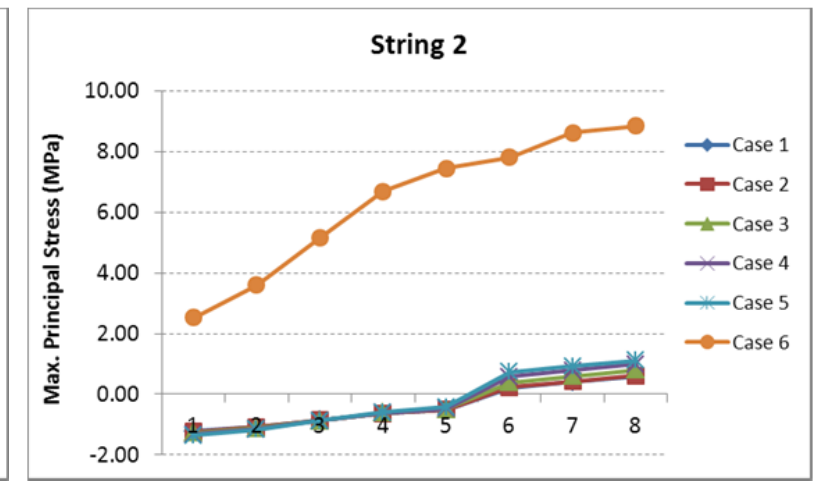

Figure 41: Maximum Principal stress at nodes in Strings 2

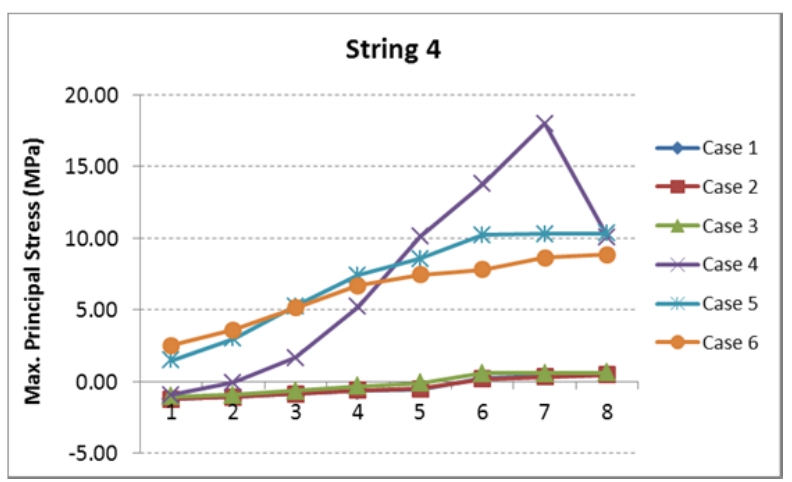

Figure 43. Maximum Principal stress at nodes in Strings 4 


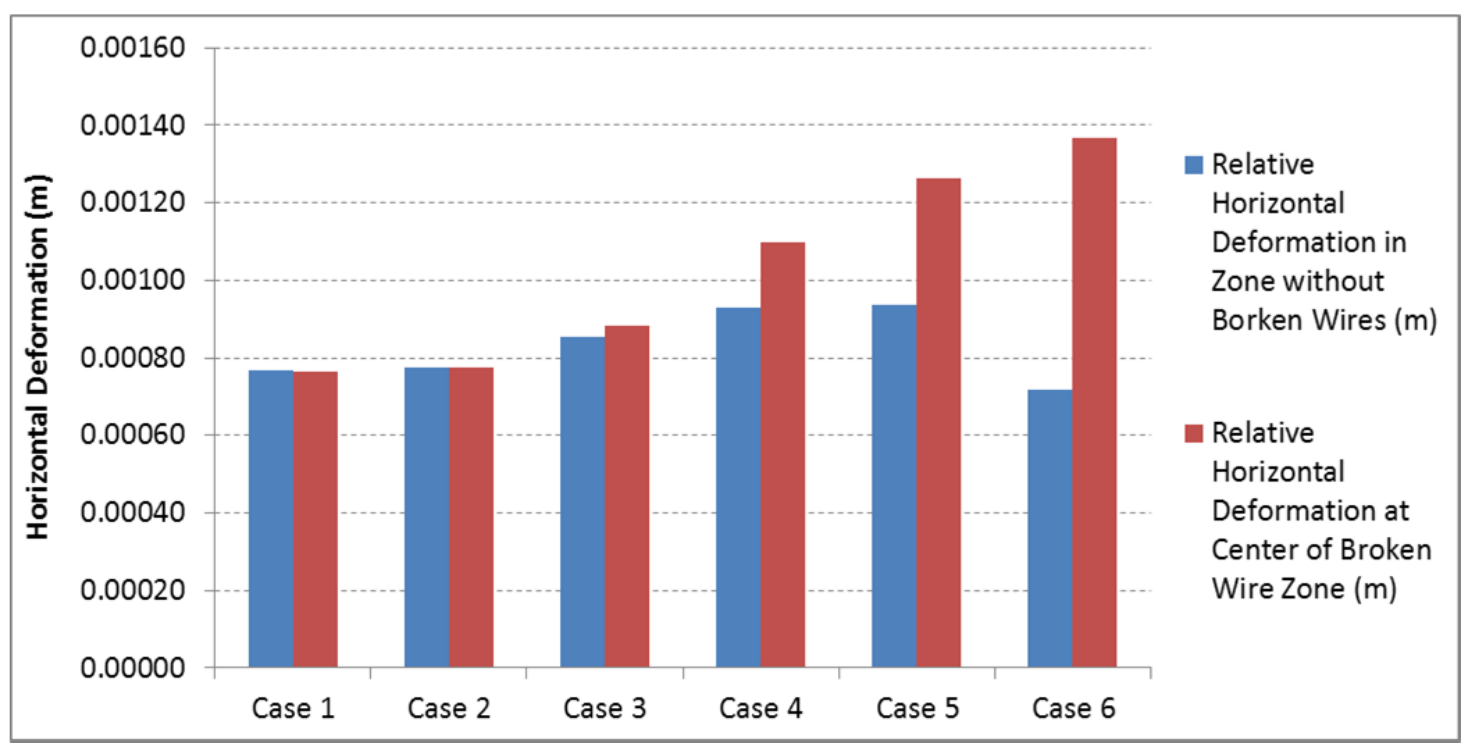

Figure 44. Horizontal deformation in the PCCP

\section{Conclusions}

The bond quality of mortar coating is a critical factor to consider in the modeling of PCCP using numerical models. Current models have very conservative assumption and remove all broken wires from the model. This could be over-conservative in cases where the mortar coating has very good bond. Even though the wire is broken, there still could be prestress remaining in a certain length of the broken wires.

To have a more realistic simulation of PCCP and to understand the effect of mortar coating's quality on the structural integrity of PCCP, this paper proposes a theoretical methodology to determine the length of wires needed to resume prestress beyond the broken point. Based on this methodology, a numerical model is established to analyze scenarios in which the mortar coating has different bond qualities. In this paper, six cases are analyzed and compared. The findings from the results indicate that even though the pipe has broken wires, however, if the mortar has good bond, the pipe is not much compromised and there could be no cracks in coating or concrete core. In contrast, if the mortar coating has poor bond, then there could be very high tensile stress exceeding the tensile strength of the mortar coating or concrete cores, causing cracks in the pipe. Compared with all other cases, the assumption of zero prestress in all broken wires could cause very high tensile stress in the pipe and cause cracks in invert, crown, and external springline of the pipe. This is overly conservative and is not consistent with most of the actual pipe failures modes, in which most pipes fail at 4 or 8 o'clock, not at invert, crown, or springlines.

The research presented in this paper highlights the importance to consider the bond quality of mortar coating and provides guidance for development of numerical models for PCCP. The findings of this research could help utilities have a better understanding of the limitations of current numerical models used for PCCP condition evaluation, and help them better manage PCCP pipelines. In this proposed model, due to the prestress change in broken wires, local stress concentration could be generated at places where the wire is cut. In future research, more work should be done to consider the prestress distribution between the broken wire point and the point where full prestress is resumed.

\section{Acknowledgement}

The development of WATER $i$ D (WATER Infrastructure Database) is funded by the Water Environment Research Foundation (WERF) under the contract INFR9SG09 and INFR10SG09 through the U.S. Environmental Protection Agency's Aging Water Infrastructure Research Program, and stems from EPA's Sustainable Water Infrastructure Initiative. The authors would like to thank the National Science Foundation (NSF) for the partial funding under the grant NSF-CMMI-0801018. We would also like to thank the support of the Sustainable Water Infrastructure Management (SWIM) Center of Excellence in the Institute of Critical Technology and Applied Science (ICTAS) at Virginia Tech. The authors also appreciate the constructive disucssions with Mr. John Marshall from J.W. Marshall and Associates, and Mr. Mike Woodcock from Washington Suburban Sanitary Commission. 


\section{References}

Alavinasab, A., Padewski, E., Holley, M., Jha, R., \& Ahmadi, G. (2010). Damage Identification Based on Vibration Response of Prestressed Concrete Pipes. In ASCE Pipelines Conf:: Climbing New Peaks to Infrastructure Reliability-Renew, Rehab, and Reinvest, Keystone, CO (pp. 909-919).

AWWA C301-07 (2007). AWWA Standard for Prestressed Concrete Cylinder Pipe, Steel-Cylinder Type. American Water Works Association, Denver, CO.

ANSI/AWWA C304-07 (2007). Design of Prestressed Concrete Cylinder Pipe. American Water Works Association, Denver, CO.

AwwaRF. (2008). Failure of Prestressed Concrete Cylinder Pipe, C301-07. AWWA Research Foundation, Denver, CO.

Bell, G. E., Kendall, D. R., \& Mulligan, S. B. (2001). An Assessment and Reliability Program for PCCP. Proc. Advances in Pipeline Engineering and Construction, American Society of Civil Engineers (pp. 1-10).

Diab, Y. G., \& Bonierbale, T. (2001). A numerical modeling and a proposal for rehabilitation of PCCPs. In Proc. Int. Conf. on Advances in Pipelines Eng. \& Constr, ASCE, San Diego, California.

Erbay, O. O., Zarghamee, M. S., \& Ojdrovic, R. P. (2007). Failure risk analysis of lined cylinder pipes with broken wires and corroded cylinder. In Int. Conf. on Pipeline Eng. and Construction (pp. 1-10).

Essamin, O., El-Sahli, K., Hovanessian, G., \& LeDiouron, T. (2005). Risk Management System for Prestressed Concrete Cylinder Pipeline: Practical Results and Experience on the Great Man Made River. Pipelines 2005 (241-251).

Galleher Jr, J. J., \& Stift, M. T. (1998). Internal inspection and database development of PCCP. In Pipelines in the Constructed Environment (pp. 721-730).

Ge, S., \& Sinha, S. (2012). Failure Analysis, Condition Assessment Technologies, and Performance Prediction of Prestressed-Concrete Cylinder Pipe: State-of-the-Art Literature Review. Journal of Performance of Constructed Facilities, 28(3), 618-628.

Gomez, R., Muñoz, D., Vera, R., \& Escobar, J. A. (2004). Structural model for stress evaluation of prestressed concrete pipe of the Cutzamala system. In Proc. Int. Conf. on Pipeline Eng. \& Constr.: What's on the Horizon, ASCE, San Diego, California.

Kola, R. (2010). Development of predictability and condition assessability indices for PCCP water mains, Master Thesis, Virginia Polytechnic Institute and State University, Blacksburg, VA.

Lee, Y. (2011). Analysis of prestressed concrete cylinder pipe for rehabilitation (Ph.D. Dissertation). University of California, Irvine, California, USA.

Lewis, R. O. (2002). Improving prestressing wire reliability in prestressed concrete cylinder pipe. Materials performance, 41(7), 48-54.

Marshall, J, Fisk, P. (2015). Measuring the Condition of Prestressed Concrete Cylinder Pipe. http://www.ndtcorporation.com/resources_1.html (Visited in January, 2015).

Ojdrovic, R. P., Zarghamee, M. S., Hegarty, J. R., and Westman, T. (2001). "Condition Assessment of a PCCP Line Accessible from Outside Only." Pipelines 2001-Advances in Pipeline Engineering \& Construction, $1-13$.

Parks, R. R., Drager, J. K., and Ojdrovic, R. P. (2001). "Condition Assessment and Rehabilitation of the Windy Gap Pipeline - An Owner's Perspective.” Pipelines 2001-Advances in Pipeline Engineering \& Construction, 1-13.

Price, R. E., Lewis, R. A., \& Erlin, B. (1998). Effects of environment on the durability of prestressed concrete cylinder pipe. In Pipelines in the constructed environment, Proceedings of the 1998 Pipeline Division Conference (pp. 584-593).

Rauniyar, S. (2013). Development of finite element model for analysis of prestressed concrete cylinder pipe embedded cylinder pipe (M.S. Thesis). University of Texas at Arlington, Texas, USA.

Romer, A., Ellison, D., Bell, G., and Clark, B. (2008). "Failure of Prestressed Concrete Cylinder Pipe.” Pipelines 2007, 1-17. 
Semanuik, S. and Mergelas, B. (2006). "Comparison of indentified distress in CCP pipelines operated by water utilities in North America." Proceedings of the ASCE Pipeline Division Specialty Conference, July 30-August 2, Chicago, Illinois, 1-8.

UIM. (2011). Prestressed Pipe Deterioration Prompts Large Utility to Seek Effective, Cost-efficient Approach. Retrieved December 29th, 2013, from http://uimonline.com/index/webapp-stories-action/id.563/archive. yes/Issue.2011-10-01/title.prestressed-pipe-deterioration-prompts-large-utility-to-seek-effective,-cost-effici ent-approach

USEPA. (2013). Miami-Dade County Clean Water Act Settlement. Retrieved May 9th, 2014, fromhttp://www2.epa.gov/enforcement/miami-dade-county-clean-water-act-settlement

Villalobos, J. L. (1998). "Effects of Prestressed Concrete Cylinder Pipe in a high chloride environment after 19 years of service." Pipelines in the Constructed Environment, ASCE, Reston, VA, 575-583.

Walsh, T. L. and Hodge, D. S. (1998). "Overcoming the challenges of replacing $20 \mathrm{~km}$ of defective $1524 \mathrm{~mm}$ diameter PCCP.” Pipelines in the Constructed Environment, ASCE, Reston, VA, 602-611.

Wardany, R. A. (2008). Condition assessment of prestressed concrete cylinder water pipes. Proceedings of 60th Annual WCWWA Conference and Trade Show (pp. 1-9).

Weare, R. E. (2007). PCCP sewerage force main structural condition assessment and asset management approach. Pipelines 2007: Advances and Experiences with Trenchless Pipeline Projects (pp. 1-11).

Woodcock, M. (2008). 48-inch PCCP Pipeline Break. Technical report, Washington Suburban Sanitary Commission, Laurel, Maryland.

WSSC (2012). 80 foot setback. Washington Suburban Sanitary Commission, Laurel, Maryland. Retrieved September 18, 2014, from http://www.wsscwater.com/file/EngAndConst/80footsetbackparts/part2.pdf

Xiong, H., Li, P., \& Li, Q. (2010). FE model for simulating wire-wrapping during prestressing of an embedded prestressed concrete cylinder pipe. Simulation Modelling Practice and Theory, 18(5), 624-636.

Zarghamee, M. S., Ojdrovic, R. P., \& Dana, W. R. (1993). Preventing coating delamination in prestressed concrete pipe. In Pipeline Infrastructure II (pp. 574-594). ASCE.

Zarghamee, M. S., \& Ojdrovic, R. P. (2001). Risk assessment and repair priority of PCCP with broken wires. In Pipelines 2001@sAdvances in Pipelines Engineering and Construction (pp. 1-8). ASCE.

Zarghamee, M. S., Eggers, D. W., \& Ojdrovic, R. P. (2002). Finite-element modeling of failure of PCCP with broken wires subjected to combined loads. In Pipelines 2002@ sBeneath Our Feet: Challenges and Solutions (pp. 1-17). ASCE.

Zarghamee, M. S., Eggers, D. W., Ojdrovic, R. P., \& Rose B. (2003). Risk analysis of prestressed concrete cylinder pipe with broken wires. Pipelines 2003 (pp. 599-609).

\section{Copyrights}

Copyright for this article is retained by the author(s), with first publication rights granted to the journal.

This is an open-access article distributed under the terms and conditions of the Creative Commons Attribution license (http://creativecommons.org/licenses/by/3.0/). 